\title{
A study on the prevalence of depression and the severity of depression in patients of chronic obstructive pulmonary disease in a semi-urban Indian population
}

\author{
Abhishek Agarwal1, Sakshi Batra1, Rajendra Prasad1, Anand Verma1, \\ Abdul Q. Jilani², Surya Kant ${ }^{3}$ \\ 1 Department of Pulmonary Medicine, Era's Lucknow Medical College and Hospital, Lucknow \\ 2 Department of Psychiatry, Era's Lucknow Medical College and Hospital, Lucknow \\ 3 Department of Respiratory Medicine, King George's Medical University, Lucknow, India
}

\begin{abstract}
The chronic obstructive pulmonary disease (COPD) is one of the few respiratory diseases which is associated with a number of comorbidities. Psychiatric disease like depression is a very important comorbidity of COPD because it decreases the feeling of wellbeing in the patient and also interferes with the compliance with medication thereby increasing the risk of hospitalization in the COPD patient. A cross-sectional study was done for two years in the department of pulmonary medicine at Era's Lucknow medical college and hospital, Lucknow. A total of 150 patients were enrolled for the study after a clinico-radiological screening for COPD and the diagnosis confirmed on spirometry. After the confirmation of the diagnosis of COPD in these patients, they
\end{abstract}

Corresponding author: Dr. Abhishek Agarwal, Department of Pulmonary medicine, Era's Lucknow Medical College and Hospital, Lucknow, India. Tel.+91.9651654676. E-mail: drabhishekrd@gmail.com

Key words: Depression; COPD; comorbidities; PHQ-9 scale; HAM-D scale.

Contributions: AA, study conception and design, data acquisition, analysis and interpretation, manuscript drafting, critical revision; $\mathrm{SB}, \mathrm{AV}$, data acquisition, manuscript drafting, critical revision; RP, study conception and design, data analysis and interpretation; $\mathrm{AQJ}$, study conception and design, data acquisition, analysis and interpretation, manuscript drafting; SK, study conception and design, data analysis and interpretation, critical revision.

Conflict of interest: The Authors declare no conflict of interest.

Work presented as Poster at the NAPCON Conference, Kolkata, India in November 2017.

Received for publication: 15 December 2017

Accepted for publication: 4 March 2018

(C) Copyright A. Agarwal et al., 2018

Tipografia PI-ME Editrice, Italy

Monaldi Archives for Chest Disease 2018; 88:902

doi: 10.4081/monaldi.2018.902

This article is distributed under the terms of the Creative Commons Attribution Noncommercial License (by-nc 4.0) which permits any noncommercial use, distribution, and reproduction in any medium. provided the original author(s) and source are credited. were screened for depression using the PHQ-9 scale in our department of pulmonary medicine. The confirmation of the diagnosis of depression was done according to the ICD-10 guidelines for depression and the severity of depression was graded using HAM-D scale in the department of psychiatry at our institute. The most common age group enrolled in the study was 51-60 years of age (40.67\%). One hundred and fifteen patients (76.7\%) of the enrolled patients were smokers while the remaining 35 patients (23.3\%) were non-smokers. Depression was found to be present in 46 out of the total 150 patients in the study. Thus, the prevalence of depression in our study was $30.67 \%$. Depression was seen in COPD groups B,C and D. Out of the 46 patients of COPD with depression, 18 had mild depression (39.13\%), 26 had moderate depression (56.52\%) and 2 had severe depression (4.35\%). Hence, depression of all grades (i.e., mild, moderate and severe depression) is seen in COPD groups $\mathrm{B}, \mathrm{C}$ and $\mathrm{D}$.

\section{Introduction}

Chronic obstructive pulmonary disease (COPD) is a chronic respiratory disease known for decades but it has gained special importance in the last few years as it is expected to be the third leading cause of death by $2020[1,2]$. COPD is one of the few respiratory diseases which is associated with a number of comorbidities like heart failure, skeletal muscle dysfunction, osteoporosis, metabolic syndrome, ischemic heart disease, pulmonary artery disease, lung cancer, peripheral vascular disease, bronchiectasis, psychiatric diseases, gastroesophageal reflux disease, sleep disturbance and obstructive sleep apnea [2]. Psychiatric disease like depression is a very important comorbidity of COPD because it decreases the feeling of wellbeing in the patient and also interferes with the compliance with medication thereby increasing the risk of hospitalization in the COPD patient.

Depression is a common psychiatric ailment in our society. It is estimated that about $4.4 \%$ of the world's population has depression [2]. The South-East Asian region alone contributes one-fourth of the global cases of depression. India itself accounts for about 18\% of the globally occurring cases of depression [3]. The prevalence of depression in India is around 15\% [4]. According to WHO, depression causes the maximum disability worldwide and is also a leading cause of suicidal deaths worldwide [5]. Depression may present as a major depressive disorder, bipolar disorder or dysthymia. Depression is characterized by low mood, fatigue, poor concentration, inadequate sleep and pessimistic ideas leading to low self esteem. All these symptoms eventually lead to poor quality of life and sometimes even suicidal thoughts in severe cases. 
The prevalence of major depression varies from $22 \%$ to $33 \%$ in patients with chronic non-communicable diseases thereby increasing the chances of developing depression six times in comparison to the general population [3]. COPD alone accounts for $6 \%$ of the global deaths [1] and patients with depression are about 1.5 times at higher risk of mortality than the general population [3]. The present study was done at our institute to determine the prevalence of depression in the COPD patients and to determine the severity of depression in various groups and spirometry grades of COPD patients.

\section{Materials and Methods}

A cross-sectional study was done for two years in the department of pulmonary medicine at Era's Lucknow medical college and hospital, Lucknow. A total of 150 patients were enrolled for the study after a clinico-radiological screening for COPD, and the diagnosis of COPD being confirmed in them by spirometry with a post-bronchodilator $\mathrm{FEV}_{1} / \mathrm{FVC}$ of $<0.70$. Consecutive COPD patients from both indoor and outdoor in the department of pulmonary medicine were included in the study. All the patients included in the study were acculturate. Patients with other chronic systemic diseases were excluded from the study. Depending on the airflow limitation, the severity of COPD was graded into GOLD 1,2,3 and 4 grades according to the post-bronchodilator $\mathrm{FEV}_{1}$ value on spirometry. Then the COPD assessment test (CAT) was applied to these patients and on the basis of their mMRC (Modified British Medical Research Council) grade of dyspnea, CAT score, previous exacerbation and hospitalization history these patients were divided into COPD groups A, B, C and D. These COPD groups determined the symptom burden in the patient and also the risk of exacerbation in the patient. As per the Global Initiative for Chronic Obstructive Lung Disease (GOLD) guideline 2017 [1], the COPD groups A, B, C and D were determined on the basis of mMRC grading of dyspnea and CAT score on the horizontal axis(x-axis) and number of exacerbations with or without hospitalization on the vertical axis (y-axis). In Group A, the COPD patients had mMRC grade ( 0 to 1$)$ and CAT score of $<10$ on horizontal axis and ( 0 or 1 ) exacerbation not leading to hospitalization on vertical axis. In Group B, the COPD patients had mMRC grade $\geq 2$ and CAT score of $\geq 10$ on horizontal axis and ( 0 or 1 ) exacerbation not leading to hospitalization on vertical axis. In Group C, the COPD patients had mMRC grade ( 0 to 1 ) and CAT score of $<10$ on horizontal axis and $\geq 2$ exacerbations not leading to hospitalization or any one exacerbation leading to hospitalization on vertical axis. In Group D, the COPD patients had mMRC grade $\geq 2$ and CAT score of $\geq 10$ on horizontal axis and $\geq 2$ exacerbations not leading to hospitalization or any one exacerbation leading to hospitalization on vertical axis.

After the confirmation of the diagnosis of COPD in these patients, the consecutive COPD patients were subjected to initial screening for depression in our pulmonary medicine department using the PHQ-9 (Patient Health Questionnaire-9) scale in which the patient answered nine questions on a scale of 0 to 3 . This PHQ-9 questionnaire helps in screening the patients for depression and also helps in predicting the severity of depression. A score of $0-4$ is not associated with any depression, 5-9 indicates mild depression, 10-14 indicates moderate depression, 15-19 indicates moderately severe depression, and 20-27 indicates severe depression. After initial screening for depression in our department, the patient was then referred to the department of psychiatry at our institute where the psychiatrist confirmed the diagnosis of depression according to the ICD-10 guidelines for depression and also graded the severity of depression using HAM-D scale (Hamilton depression rating scale). The first seventeen questions in the HAM-D scale are included in the scoring of the severity of depression while the next four questions are not included in the scoring and they determine the presence of diurnal variation, depersonalization and derealization, paranoid and obsessive-compulsive symptoms in the patient. In the HAM-D scale a score of 0-7 is taken as normal, 8-13 indicates mild depression, 14-18 indicates moderate depression, 19-22 indicates severe depression, and $\geq 23$ indicates very severe depression.

Informed consent was taken from all the subjects. The approval for the study was taken from the institute's ethical committee.

\section{Statistical analysis}

All statistical analyses were performed using SPSS statistical software 17.0 (SPSS Inc., USA). Descriptive statistics of all continuous variables were calculated as means and standard deviation while the categorical data were expressed as percentages. A comparison between groups was done using Student's $t$-test for continuous variables and chi-square test or Mann Whitney U test was used for discrete variables. Rate differences between variables were calculated by odd ratios (ORs) and the corresponding 95\% confidence intervals (CIs). A p-value of $<0.05$ was considered statistically significant.

\section{Results}

A total of 150 patients were enrolled for the study of which 110 were males (73.33\%) and 40 were females (26.67\%). The most common age group enrolled in the study was 51-60 years of age at (40.67\%). However, in COPD patients with depression the most common age group was 61-70 years at (43.48\%) and this was statistically significant with a p-value of 0.002 . Out of the total 150 patients of COPD, 15 patients (10\%) were illiterate while 30 patients (20\%) were semiliterate and remaining 105 patients (70\%) were full literate (Table 1). One hundred and fifteen patients (76.67\%) were current or ex-smokers, while the remaining 35 patients (23.33\%) were never smokers. The most common smoking pattern was bidi smoking at $73.0 \%$ followed by cigarette smoking at $22.6 \%$ and hukka smoking at $4.4 \%$. The smoking pack-year of about 22 packs/year and those COPD patients who had left smoking about two years back were more predisposed to depression and this association was statistically significant with a p-value of 0.002 (Table 1). History of biomass fuel exposure was present in $34.0 \%$ of the patients. The average HAM-D score in the COPD patients with depression was 13.89 and this was statistically significant with a p-value of $<0.001$ (Table 1 ). There were no false positive patients of depression by PHQ-9 screening in comparison to the HAM-D scale. However, the correlation between PHQ-9 score and HAMD score for diagnosing the severity of depression was weak and not statistically significant with a p-value of 0.911 . Depression was found to be present in 46 out of the total 150 patients in the study.Thus the prevalence of depression in our study was $30.67 \%$ (Table 2). In COPD patients with depression, 15 patients (32.61\%) had mMRC grade 4 dyspnea while 11 patients (23.91\%) had mMRC grade 3 dyspnea (Table 3 ). In COPD patients without depression, only 8 patients (7.69\%) had mMRC grade 4 dyspnea while 30 patients (28.85\%) had mMRC grade 3 dyspnea (Table 3). Thus the prevalence of depression was higher amongst patients with mMRC grade 4 dyspnea and this difference was statistically significant with a p-value of 0.015 .However, the difference in CAT score was not statistically significant in the patients of COPD with depression and those without depression (Table 3). The COPD exacerbation history of $\geq 2$ previous exacerbations and any exacerbation leading to hospitalization were more in the patients of COPD with depression in comparison to the COPD patients without depression and this difference was statistically significant with a p-value $<0.001$ (Table 4 ). 
Out of the 46 patients of COPD with depression, 25 patients (54.35\%) were of COPD group D while 15 patients (32.61\%) were of COPD group $C$ and only 6 patients (13.04\%) were of COPD group B. The higher percentage of depression patients in COPD group D in comparison to the other COPD groups was statistically significant with a pvalue $<0.001$ (Table 5). The division of these patients as per the severity of depression showed that all the 6 patients of group B had mild depression. Amongst the 15 patients of group C, 7 patients had mild depression while 8 patients had moderate depression. Lastly, out of the 25 patients in group D, 5 patients had mild depression, 18 patients had moderate depression and 2 patients had severe depression. No evidence of depression was found in group A patients. The increased number of depression patients and the increased severity of depression in Group D patients in comparison to Group B and C was statistically significant with a p-value of 0.025 (Table 6 ). The severity of depression as per the spirometry grading showed that in GOLD grade 1 there were 2 patients of mild depression while in GOLD grade 2 there were 7 patients of mild depression and 2 patients of moderate depression. In GOLD grade 3 there were 4 patients of mild depression and 10 patients of moderate depression. Finally, in GOLD grade 4, there were 5 patients of mild depression, 14 patients of moderate depression and 2 patients of severe depression. The increased number of depression patients and the increased severity of depression in GOLD grade 4 patients in comparison to GOLD grade 2 and 3 was statistically significant with a p-value of 0.038 (Table 7). Hence, out of the 46 patients of COPD with depression, 18 patients (39.13\%) had mild depression, 26 patients (56.52\%) had moderate depression and 2 patients (4.35\%) had severe depression.

\section{Discussion}

COPD itself is a progressive disease and the association of several comorbidities with COPD further adds to the severity of the disease in the patient. Despite of the several novel medications and techniques for treatment of COPD, it is still the fourth leading cause of death globally [1]. It is very important to identify and treat the comorbidities associated with COPD so as to decrease the overall mortality due to

Table 1. Demographic profile of COPD patients with and without depression ( $n=150)$.

\begin{tabular}{|c|c|c|c|}
\hline Variables & $\begin{array}{c}\text { COPD patients with depression }(\mathrm{n}=46) \\
\text { Number }(\%)\end{array}$ & $\begin{array}{l}\text { COPD patients without depression ( } \mathrm{n}=104) \\
\text { Number }(\%)\end{array}$ & p-value \\
\hline Age in years & & -3 & \\
\hline $41-50$ & $9(19.57 \%)$ & $37(35.58 \%)$ & 0.002 \\
\hline $51-60$ & $14(30.43 \%)$ & $47(45.19 \%)$ & \\
\hline $61-70$ & $20(43.48 \%)$ & $16(15.38 \%)$ & \\
\hline$>70$ & $3(6.52 \%)$ & $4(3.85 \%)$ & \\
\hline \multicolumn{4}{|l|}{ Gender } \\
\hline Male & $29(63.04 \%)$ & $81(77.88 \%)$ & 0.09 \\
\hline Female & $17(36.96 \%)$ & $23(22.12 \%)$ & \\
\hline \multicolumn{4}{|l|}{ Level of education } \\
\hline Less than High School & $10(21.74 \%)$ & $20(19.23 \%)$ & 0.99 \\
\hline High School & $06(13.04 \%)$ & $16(15.38 \%)$ & \\
\hline Intermediate & $05(10.86 \%)$ & $13(12.50 \%)$ & \\
\hline Graduate & 09 (19.57\%) & $18(17.31 \%)$ & \\
\hline Postgraduate & $12(26.09 \%)$ & $26(25.00 \%)$ & \\
\hline Illiterate & $04(8.70 \%)$ & $11(10.58 \%)$ & \\
\hline \multicolumn{4}{|l|}{ Smoking history } \\
\hline Never smoker & $14(30.43 \%)$ & $21(20.19 \%)$ & 0.21 \\
\hline Ex-smoker & 27 (58.70\%) & $58(55.77 \%)$ & \\
\hline Current smoker & $05(10.87 \%)$ & $25(24.04 \%)$ & \\
\hline Pack-years & $22.95 \pm 7.88$ & $17.66 \pm 8.09$ & 0.002 \\
\hline Biomass fuel exposure & 17 (36.95\%) & $34(32.70 \%)$ & 0.71 \\
\hline HAM-D score average & $13.89 \pm 3.67$ & $5.25 \pm 0.92$ & $<0.001$ \\
\hline
\end{tabular}

Table 2. Distribution of COPD patients depending on presence and absence of depression $(\mathrm{n}=150)$.

\begin{tabular}{lccc} 
COPD & Depression & Number of patients & \multicolumn{2}{c}{ Percentage } \\
Present & Present & 46 & 30.67 \\
\hline Present & Absent & 104 & 69.33 \\
\hline
\end{tabular}


COPD. Depression is one of the important comorbidities of COPD as depression is associated with a feeling of increased dyspnea leading to more hospitalization of COPD patients [2]. The overall prevalence of depression increases in patients with chronic illnesses and has been found to be 9 to $23 \%$ [6]. Depression can be easily screened for in any setting using the PHQ-9 scale.The PHQ-9 scale is a commonly used validated tool for screening depression [7]. The internal reliability and the test-retest reliability of the PHQ-9 scale has been found to be excellent with the positive predictive value of the scale being $51 \%$ for diagnosing major depression at a cut off value of 15 [8]. The sensitivity, specificity and overall accuracy of PHQ-9 scale for screening for any depressive disorder is higher in comparison to other scales like HADS (Hospital Anxiety and Depression Scale) and WBI-5 (WHO WellBeing Index-5) [9]. After the diagnosis of depression by the ICD-10 guidelines, the severity of depression can be determined by HAM-D scale which has been considered the gold standard for assessing the severity of depression and has been widely used for this purpose [10]. HAM-D scale has also been used to assess response to treatment in patients of depression in clinical trials [11]. A modified form of HAM-D known as HAM-D-6 scale can also be used for screening for depression. HAM-D-6

Table 3. mMRC grading of dyspnea and CAT score in COPD patients with and without depression.

\begin{tabular}{|c|c|c|c|c|c|c|}
\hline \multirow[t]{2}{*}{$\begin{array}{l}\text { mMRC grade } \\
\text { of dyspnea }\end{array}$} & \multicolumn{2}{|c|}{$\begin{array}{l}\text { COPD patients } \\
\text { with depression } \\
\quad(n=46)\end{array}$} & \multicolumn{2}{|c|}{$\begin{array}{l}\text { COPD patients } \\
\text { without depression } \\
\qquad(\mathrm{n}=104)\end{array}$} & \multicolumn{2}{|c|}{$\begin{array}{l}\text { Total number } \\
\text { of patients in studs } \\
(n=150)\end{array}$} \\
\hline & Number & $\%$ & Number & $\%$ & Number & $\%$ \\
\hline 1 & 15 & 32.61 & 41 & 39.42 & 56 & 37.33 \\
\hline 2 & 5 & 10.87 & 25 & 24.04 & 30 & 20.00 \\
\hline 3 & 11 & 23.91 & 30 & 28.85 & 41 & 27.33 \\
\hline \multirow[t]{2}{*}{4} & 15 & 32.61 & 8 & 7.69 & 23 & 15.33 \\
\hline & \multicolumn{6}{|c|}{$\begin{array}{c}Z=2.444 ; p=0.015 \\
\text { (Mann Whitney U test) }\end{array}$} \\
\hline \multicolumn{7}{|l|}{ CAT Score } \\
\hline$<10$ & 15 & 32.61 & 41 & 39.42 & 56 & 37.33 \\
\hline$\geq 10$ & 31 & 67.39 & 63 & 60.58 & 94 & 62.67 \\
\hline
\end{tabular}

Table 4. Association of COPD exacerbations (with and without hospitalization) with the prevalence of depression in COPD patients.

\begin{tabular}{|c|c|c|c|c|c|c|}
\hline \multirow[t]{2}{*}{ Variables } & \multicolumn{2}{|c|}{$\begin{array}{l}\text { COPD patients } \\
\text { with depression } \\
(\mathrm{n}=46)\end{array}$} & \multicolumn{2}{|c|}{$\begin{array}{l}\text { COPD patients } \\
\text { without depression }) \\
\qquad(n=104)\end{array}$} & \multicolumn{2}{|c|}{$\begin{array}{l}\text { Total number } \\
\text { of patients in study } \\
(\mathrm{n}=150)\end{array}$} \\
\hline & Number & $\%$ & Number & $\%$ & Number & $\%$ \\
\hline \multicolumn{7}{|l|}{ COPD exacerbations without hospital admission } \\
\hline 0 & 0 & 0.00 & 39 & 37.50 & 39 & 26.00 \\
\hline  & 6 & 13.04 & 23 & 22.12 & 29 & 19.33 \\
\hline$\sqrt{2+2}$ & 24 & 52.17 & 37 & 35.58 & 61 & 40.67 \\
\hline \multicolumn{7}{|l|}{ COPD exacerbation with hospital admission } \\
\hline Any exacerbation requiring hospitalization & 16 & 34.78 & 5 & 4.81 & 21 & 14.00 \\
\hline
\end{tabular}

Table 5. Distribution of depression patients amongst the different groups of COPD patients.

\begin{tabular}{|c|c|c|c|c|}
\hline \multirow[t]{2}{*}{ COPD Group } & \multicolumn{2}{|c|}{$\begin{array}{l}\text { COPD patients } \\
\text { with depression } \\
(\mathrm{n}=46)\end{array}$} & \multicolumn{2}{|c|}{$\begin{array}{l}\text { COPD patients } \\
\text { without depression } \\
(\mathrm{n}=104)\end{array}$} \\
\hline & Number & $\%$ & Number & $\%$ \\
\hline A & 0 & 0.00 & 7 & 6.73 \\
\hline B & 6 & 13.04 & 55 & 52.88 \\
\hline $\mathrm{C}$ & 15 & 32.61 & 34 & 32.69 \\
\hline D & 25 & 54.35 & 8 & 7.69 \\
\hline
\end{tabular}


consists of six items namely depressed mood, guilt feelings, work and interest, retardation, psychic anxiety and general somatic. A score of $\geq 10$ in HAM-D-6 scale is an indication for treatment with an antidepressant drug [12].

The prevalence of depression in COPD patients has been found to be $30.67 \%$ in our study. Depression is common in COPD patients and its prevalence has been reported to be varying between 7 to $55 \%$ in various studies [12-15]. The most common age group of COPD patients diagnosed with depression in our study was between 61-70 years. Males constituted about two-thirds of the COPD patients with depression in our study. However, according to some studies age and gender do not affect the prevalence of depression in COPD patients [16,17]. In our study about $73 \%$ of the study population were males and possibly this could have led to the increased diagnosis of depression amongst males in our study. Smoking pack-year of about 22 packs/year and ex-smokers who had left smoking about two years back were more predisposed to depression. However, Biswas et al. [17] and Pascal et al. [18] did not find any significant association between the smoking status as current or ex-smoker and smoking index(or pack year) with the prevalence of depression in COPD patients.COPD patients with $\geq 2 \mathrm{mMRC}$ grade of dyspnea have been found to be more prone to develop depression [19]. In our study, depression was diagnosed in COPD patients with all grades of dyspnea but there was significant increase in percentage of depression cases amongst patients with mMRC grade 4 dyspnea.

In our study, increased prevalence of depression was seen in COPD patients with $\geq 2$ previous exacerbations without hospitalization and in those COPD patients with a history of hospitalization. Depression is a known risk factor for increased moderate to severe exacerbations along with increased risk of hospitalization and also longer hospital stay in COPD patients [20-23]. In our study depression was seen in all groups and spirometry grades of COPD patients. However, there were 25 cases (54.35\%) of depression in group D alone. Similarly, there were 21 cases (45.65\%) of depression in spirometry GOLD grade 4.The number of cases of depression in group D and spirometry GOLD grade 4 of COPD were the highest in comparison to the other groups and spirometry grades of COPD.Severe depression was seen only in group D and GOLD grade 4 of COPD patients. Depression has been reported in all stages of COPD by other studies also and the severity of depression along with the risk of developing depression has been found to increase with the increase in severity of COPD [24-26]. Use of long-term oxygen therapy further increases the prevalence of depression in COPD patients [2627]. As per the severity of depression in COPD patients in our study, the maximum percentage of patients at $56.52 \%$ had moderate depression followed by mild depression and then severe depression. As many patients of COPD had mild depression, hence efforts should be made to diagnose depression when it is of mild severity so as to minimize its implications in COPD patients. Depression in COPD patients is also associated with increased readmission rates $[28,29]$ and increased mortality [30].

The causes of depression in COPD patients are multifactorial but patients with higher disease acceptance and higher disease limitations acceptance have been found to have lower rate of depression. Similarly patients with less mild cognitive impairment and good familial support have been found to be lesser depressed [31]. Hence, patients of COPD with depression should attend pulmonary rehabilitation program where the patient learns about breathing techniques, nutrition, medicines, relaxation techniques and the methods through which the patient will remain healthy and will avoid frequent exacerbations. Through this program the patient also receives emotional support and is taught the methods to withstand COPD comorbidities like depression, osteoporosis and muscle wasting. The family members should be guided to be very supportive to the patient. Educating the patient and the family members about the course of the disease and the importance of adherence to the medications should also be stressed.

Majority of the COPD patients with depression have been found to have mild to moderate depression which is amenable to treatment with cognitive behavioral therapy (CBT) and antidepressant medication. CBT has been used both for the acute treatment of depression and for the continuation and maintenance treatment of depression [32]. CBT causes a reduction in residual symptoms and also decreases the

Table 6. Distribution of depression patients according to their severity amongst the different groups of COPD patients(n=46).

\begin{tabular}{|c|c|c|c|c|c|c|}
\hline \multirow[t]{3}{*}{ COPD Group } & \multicolumn{6}{|c|}{ Severity of depression } \\
\hline & \multicolumn{2}{|c|}{ Mild } & \multicolumn{2}{|c|}{ Moderate } & \multicolumn{2}{|c|}{ Severe } \\
\hline & Number & $\%$ & Number & $\%$ & Number & $\%$ \\
\hline Group A & 0 & 0.00 & 0 & 0.00 & 0 & 0.00 \\
\hline Group B & 6 & 100.00 & 0 & 0.00 & 0 & 0.00 \\
\hline Group C & 7 & 46.67 & 8 & 53.33 & 0 & 0.00 \\
\hline \multirow[t]{2}{*}{ Group D } & 5 & 20.00 & 18 & 72.00 & 2 & 8.00 \\
\hline & \multicolumn{6}{|c|}{$\chi^{2}=14.39(d f=6) ; p=0.025$} \\
\hline
\end{tabular}

Table 7. Distribution of depression patients according to their severity amongst the different spirometry grades of COPD patients ( $\mathrm{n}=46$ ).

\begin{tabular}{|c|c|c|c|c|c|c|}
\hline \multirow[t]{3}{*}{ Spirometry grading of COPD } & \multicolumn{6}{|c|}{ Severity of depression } \\
\hline & \multicolumn{2}{|c|}{ Mild } & \multicolumn{2}{|c|}{ Moderate } & \multicolumn{2}{|c|}{ Severe } \\
\hline & Number & $\%$ & Number & $\%$ & Number & $\%$ \\
\hline GOLD grade 1 & 2 & 100.00 & 0 & 0.00 & 0 & 0.00 \\
\hline GOLD grade 2 & 7 & 77.77 & 2 & 22.22 & 0 & 0.00 \\
\hline GOLD grade 3 & 4 & 29.57 & 10 & 71.43 & 0 & 0.00 \\
\hline \multirow[t]{2}{*}{ GOLD grade 4} & 5 & 23.81 & 14 & 66.67 & 2 & 9.52 \\
\hline & \multicolumn{6}{|c|}{$\chi^{2}=13.31(d f=6) ; p=0.038$} \\
\hline
\end{tabular}


chances of relapse of depressive symptoms [33,34]. CBT causes significant reduction in the treatment cost of depression in the patients [35]. Apart from CBT, the patients of depression can be given interpersonal psychotherapy, family and couples therapy and problemsolving therapy. Patients of depression will benefit from relaxation techniques like progressive muscle relaxation and exercise in the form of walking, running or cycling. These patients should also indulge in positive and pleasurable activities.

This study detects depression in a substantial number of COPD patients especially in COPD groups $\mathrm{C}$ and $\mathrm{D}$. But the sample size in our study is small which is a major limitation of our study. More studies with larger sample size are required to postulate these results to the COPD patients in general. Moreover, study of larger number of COPD patients of Groups A and B may reveal a higher prevalence of depression in these groups of COPD patients than reported in our study.

\section{Conclusions}

Depression is an important comorbidity of COPD associated with increased risk of exacerbation, hospital admission and mortality in COPD patients. Depression is also associated with poor adherence to treatment in COPD patients [36] along with decreased number of visits in the outpatient department (OPD) by the patient to the treating doctor and also inadequate participation of the patient in pulmonary rehabilitation programmes [37]. About one-third of COPD patients suffer from depression and hence patients with increased symptoms or frequent exacerbations should be screened for depression.

\section{References}

1. Global Initiative for Chronic Obstructive Lung Disease (GOLD) 2017. Global strategy for the diagnosis, management and prevention of chronic obstructive pulmonary disease, 2017 report. Available from: http://www.goldcopd.org

2. Cavailles A, Brinchault-Rabin G, Dixmier A, et al. Comorbidities of COPD. Eur Resp Rev 2013;22:454-75.

3. WHO. Depression in India Let's talk 5_April 2017 Rev.cdr. World Health Organization 2017. Available from: http://www.searo.who. int/india/depression_in_india.pdf

4. Pattanayak RD, Sagar R. Depressive disorders in Indian context: a review and clinical update for physicians. J Assoc Physicians India. 2014;62:827-32.

5. WHO. Depression and other common mental disorders: Global Health Estimates. Geneva, World Health Organization; 2017.

6. Kessler RC, Bromet EJ. The epidemiology of depression across cultures. Annu Rev Public Health.2013;34:119-38.

7. Maurer DM. Screening for depression. Am Fam Physician 2012;85:139-44.

8. Kroenke K, Spitzer RL, Williams JB. The PHQ-9: validity of a brief depression severity measure. J Gen Intern Med 2001;16:606-13.

9. Lowe B, Spitzer RL, Grafe K, et al. Comparative validity of three screening questionnaires for DSM-IV depressive disorders and physicians' diagnoses. J Affect Disord 2004;78:131-40.

10. Edelstein BA, Drozdick LW, Ciliberti CM. Assessment of depression and bereavement in older adults. Handbook of Assessment in Clinical Gerontology. 2010: pp. 3-43.

11. Maust D, Cristancho M, Gray L, et al. Psychiatric rating scales. M. J. Aminoff, F. Boller, D.F. Swaab, Editors. Handbook of Clinical Neurology. 2012, vol. 106, pp. 227-237.
12. Stage KB, Middelboe T, Stage TB, Sorensen CH. Depression in COPD-management and quality of life considerations. Int J Chron Obstruct Pulmon Dis 2006;1:315-20.

13. Di Marco F, Verga M, Reggente M, et al. Anxiety and depression in COPD patients: The roles of gender and disease severity. Respir Med 2006;100:1767-74.

14. Mikkelsen RL, Middelboe T, Pisinger C, Stage KB. Anxiety and depression in patients with chronic obstructive pulmonary disease (COPD). A review. Nord J Psychiatry 2004;58:65-70.

15. Lou P, Zhu Y, Chen P, et al. Prevalence and correlations with depression, anxiety and other features in outpatients with chronic obstructive pulmonary disease in China: a cross-sectional case control study. BMC Pulm Med 2012;12:53-61.

16. Elassal G, Elsheikh M, Zeid AGA. Assessment of depression and anxiety symptoms in chronic obstructive pulmonary disease patients: A case-control study. Egypt J Chest Dis Tuberc 2014;63:575-82.

17. Biswas D, Mukherjee S, Chakroborty R, et al. Occurrence of anxiety and depression among stable COPD patients and its impact on functional capability. J Clin Diagn Res 2017;11:24-7.

18. Pascal OI, Trofor AC, Lotrean LM, et al. Depression, anxiety and panic disorders in chronic obstructive pulmonary disease patients: correlations with tobacco use, disease severity and quality of life. Tob Induc Dis 2017;15:23-7.

19. Miravitlles M, Molina J, Quintano JA, et al. Factors associated with depression and severe depression in patients with COPD. Respir Med 2014;108:1615-25.

20. Laurin C, Moullec G, Bacon SL, Lavoie KL. Impact of anxiety and depression on chronic obstructive pulmonary disease exacerbation risk. Am J Respir Crit Care Med.2012;185:918-23.

21. Yohannes AM, Mulerova H, Lavoie K, et al. The association of respiratory symptoms with rates of acute exacerbations in patients with COPD: Results from a 3-year longitudinal follow-up of the ECLIPSE cohort. J Am Med Dir Assoc 2017;18:955-9.

22. Wilson I. Depression in the patient with COPD. Int J Chron Obstruct Pulmon Dis 2006;1:61-4.

23. Xu W, Collet JP, Shapiro S, et al. Independent effect of depression and anxiety on chronic obstructive pulmonary disease exacerbations and hospitalizations. Am J Respir Crit Care Med 2008;178:913-20.

24. De S. Prevalence of depression in stable chronic obstructive pulmonary disease. Indian J Chest Dis Allied Sci 2011;53:35-9.

25. van Manen JG, Bindels PJ, Dekker FW, et al. Risk of depression in patients with chronic obstructive pulmonary disease and its determinants. Thorax 2002;57:412-6.

26. Yohannes AM, Alexopoulos GS. Depression and anxiety in patients with COPD. Eur Respir Rev 2014;23:345-9.

27. Lacasse Y, Rousseau L, Maltais F. Prevalence of depressive symptoms and depression in patients with severe oxygen-dependent chronic obstructive pulmonary disease. J Cardiopulm Rehabil 2001;21:80-6.

28. Singh G, Zhang W, Kuo YF, Sharma G. Association of psychological disorders with 30 -day readmission rates in patients with COPD. Chest 2016;149:905-15.

29. Iyer AS, Bhatt SP, Garner JJ, et al. Depression is associated with readmission for acute exacerbation of chronic obstructive pulmonary disease. Ann Am Thorac Soc 2016;13:197-203.

30. Ouellette DR, Lavoie KL. Recognition, diagnosis and treatment of cognitive and psychiatric disorders in patients with COPD. Int $\mathrm{J}$ Chron Obstruct Pulmon Dis 2017;12:639-50.

31. Pierobon A, Sini Bottelli E, Ranzini L, et al. COPD patients' self-reported adherence, psychosocial factors and mild cognitive impairment in pulmonary rehabilitation. Int J Chron Obstruct Pulmon Dis 2017;12:2059-67. 
32. Driessen E, Hollon SD. Cognitive behavioral therapy for mood disorders: efficacy, moderators and mediators. Psychiatr Clin North Am 2010;33:537-55.

33. Powell VB, Abreu N, de Oliveira IR, Sudak D. Cognitive-behavioral therapy for depression. Rev Bras Psiquiatria 2008;30:S73-80.

34. Kennard BD, Emslie GJ, Mayes TL, et al. Sequential treatment with fluoxetine and relapse-prevention CBT to improve outcomes in pediatric depression. Am J Psychiatry 2014;171:1083-90.

35. Watanabe N, Furukawa TA, Shimodera S, et al. Cost-effectiveness of cog- nitive behavioral therapy for insomnia comorbid with depression: Analysis of a randomized controlled trial. Psychiatry Clin Neurosci 2015;69:335-43.

36. DiMatteo MR, Lepper HS, Croghan TW. Depression is a risk factor for noncompliance with medical treatment: meta-analysis of the effects of anxiety and depression on patient adherence. Arch Intern Med 2000;160:2101-7.

37. Fan VS, Giardino ND, Blough DK, et al. Costs of pulmonary rehabilitation and predictors of adherence in the National Emphysema Treatment Trial. COPD 2008;5:105-16. 